\title{
Application and Development of Splicing Technology in Costume Design
}

\author{
Xiaoli Luan \\ Jiangxi Institute of Fashion Technology, Nanchang, 330201, China
}

Keywords: splicing technology; costume design; application and development

\begin{abstract}
The costume designers take advantage of new design method - splicing technology to carry out breakthrough reform in costume design. As for splicing technology, it belongs to a kind of new design concept; it can create a unique effect in costume design, and also can realize people's high-standard requirement for costume design.
\end{abstract}

\section{Introduction}

The splicing technology belongs to a kind of decorative means and artistic style with historical background. Its style is to carry out splicing for cloth of same or different specification, same or different materials, same or different color in a large or small size so as to realize colorful effect of costume design. This style not only appears in ancient time, but also attracts wide attention in modern society. Especially in China, since women's dress in Sui and Tang Dynasty, we can see splicing technology both in folk and in imperial palace, in fashion circle and in daily life, in minorities' costume design and song \& dance performance or costume customizing. Furthermore, the splicing technology is integrated with various art industries. So far, it has become a kind of very fashionable artistic style in current society.

\section{Connotation of splicing technology in costume}

As for development from splicing art to splicing costume, the thinking transformation shall be made in whole links. The splicing art is formed according to ideas; when we intend to design unique painting form, we can blend some non-traditional painting materials into the form to finally complete the substance of splicing art. For instance, we make design for artistic works of different fields and styles through a kind of deep and steam-of-consciousness splicing way to realize the purpose of re-creation.

Except for "connecting”, it is also required to pay attention to "pasting" in formation of splicing technology in costume design; those are decoration methods through which some scattered clothes can be combined in an ordered or disordered way based on original cloth to design costume in a "pasting” way. Therefore, as for splicing technology, the key is the craft of art about how to splice and combine clothes of same or different color, same or different quality. Because the cloth itself has certain functional effect, the cloth of different color or quality can also play a decorating role. By comparison with "pasting" design means, the splicing technology is more practical and it also has obvious visual shocking power. Therefore, the costume splicing technology also belongs to a collage craft in artistic style.

\section{Causes of splicing technology in costume design}

\section{Economic factor}

In both Asian countries and European countries, the costume designed via splicing technology is closely related with social economy. In terms of technical practicability, as for many countries, the splicing technology has a long historical development time, and it even appeared in ancient times. Its formation starts from folk lower class with lagged economy and low social status.

\section{Cultural factor}

As for costume design, the cloth, pattern or style have experienced many reforms in their development process and have broken through their original decorative style. As for pop artist Andy Wanhol, he introduced this kind of new design style and concept into costume design; this reform 
brought great shock to costume circle in 1960s and also affected the development of future costume industry. Under pop function, more and more splicing technologies are applied in costume design; in splicing of various elements, the costume design ignores display of individuality, but obtains rich artistic value. When the costume designers make creation, they often make use of splicing and comprehensive technology to make design. The splicing technology brought by pop art is not only splicing of different materials, but also a combination of different styles, different schools, different regions and nationalities. In this process, the novel design can be highlighted.

\section{Aesthetic demand}

In 1960s, the biggest concern in European costume design was splicing technology, and many American women also regarded splicing technology as a kind of unique means of artistic expression; as for current society, it could be called one of the most classic artistic design in the United States. With development of history and change of people's life, the artists' creation materials were also continuously expanded and developed as the social economy, high technology, and information industry develop. In 1971, Whitney Museum of American Art showed splicing artworks for the first time. Since then, the social status of splicing technology was continuously improved and the splicing and combination of different fabrics become a kind of visual design. So far, the splicing also belongs to a kind of modern art.

\section{Styles reflected by splicing technology in costume design}

\section{National style}

The national style has a wide definition, and it stands for integration of traditional color and pattern features, style, and costume creation of one nationality to form a unique costume creation method. The reason why the splicing is popular and why it can be widely applied in costume industry is closely related to features of splicing. The national costume is firstly formed in folk, which is similar to costume design of splicing technology. However, the key in national style of costume design is selection of cloth and color. For example, African people's national costume focuses on color complementation in terms of splicing technology so as to realize visual shocking effect and highlight roughness and wildness of design works.

\section{Hippies style}

The first impression of hippies left on people is rebellious and free young people with disordered surface, strong color, and various styles. In order to highlight this feature, it is usually required to add triangular block or some rectangular cloth strips so as to show the features of splicing. According to specific condition, the lace, tassels, or other things can be matched as decoration. Certainly, it is able to select different cloth materials for splicing, or use cloth of different texture for combination. Through splicing of those rough and wild cloth materials, it is able to show the features of freedom, random, and no restraint.

\section{Deconstructivism style}

The deconstructivism actually refers to dissection and analysis on structuralism. In clothing industry, the splicing technology has unique religious and cultural atmosphere; due to jump, isolation, and piecing way, it is able break through conflict on costume structure and highlight mystery and stability of design style. However, as for costume design of splicing technology, by comparison with deconstructivism design, it seems that there exists relation between strategy and purpose. It seems that the deconstructivism has more individuality and mental strength and can express some conscious features against traditional thoughts. However, the splicing technology is different; it has certain historical background and belongs to a kind of artistic style which continuously develops in historical occasions. Superficially, there exists certain conflict between deconstructivism and splicing technology, but they can be still connected together. We can use splicing technology to make creation; for example, when we design costume, we match underwear with incomplete, holey, and worn-out style. All of those are considered according to structure situation, and the splicing technology can be used to show features of deconstructivism.

\section{Op style}

The op art refers to visual artistic effect. In 1960s, the op art became popular in western countries. 
It can make adjustment on dotted-line structure of 2D space and abstract spatial shape, and then change the direction to adjust the size of shape; the black, white, or other strong colors are adopted in matching to realize visual shocking and bring people a kind of illusory feeling; in this way, it is able to realize the purpose of changing 2D space into 3D space. The large, small, or sparse combination or regular or irregular sequencing of geometric shape are mainly color matching and contrast to bring a visual disordered feeling; this is same as requirements of splicing art, that is, it is able to realize op visual effect. Through adopting splicing method, it is not only able to let this kind of visual art form certain shocking power, but also able to flexibly apply this visual effect through enhancing or weakening adjustment based on texture features of textile fabrics.

\section{Application of splicing technology in costume design}

\section{Functional splicing application}

The functional splicing refers to the situation that the splicing technology has certain functional features in costume design. In case of small-area use of splicing technology, it is able to consider the part design of costume, such as front opening, bottom pendulum, joint, and edges which are easily contaminated. This kind of design is made in order to guarantee abrasion resistance of costume. In later development, the functionality-centered splicing with decorative effect is gradually formed.

\section{Decorative splicing application}

\section{Fabric splicing}

For a long time, the costume design of splicing technology has a narrow scope of fabric selection; generally, the "cloth" is used as raw materials to make design, thus the splicing technology in traditional concept is also called "cloth splicing”. However, with continuous development of the society, great changes have happened in clothing industry; the formation of fiber technology, appearance of new raw materials, and more and more perfect texture features of raw materials attract the society's wide attention; as for many costume designers, they also pay more and more attention to design requirements of beautiful texture and future sense. Meanwhile, the raw materials of non-traditional also have obvious "incompleteness" and "defect" feature; upon design, the materials are applied in small area; due to those features, the design method of splicing technology is also affected. Many designers are accustomed to blend traditional art with splicing technology together, such as China's wax printing and embroidery art. Therefore, the application of splicing technology in costume design is not merely splicing between fabric and fabric. As for its future development, such application is also a kind of innovative concept with market prospect.

\section{Color and pattern splicing}

(1) Same material and color, but different pattern. Generally speaking, if we make use of pattern to carry out splicing design and adopt high proportion of same color, the costume can easily attract people's attention. Certainly, the change of pattern is fixed; if the color is different, the costume will look disordered. (2) Same material and pattern, but different color. If the overall ranking of pattern is regular, or the regular largening or diminishing happens, the selection of color will become more random. (3) Same material, different color, and no pattern. If we have no pattern and only depend on color to carry out visual design, we shall make selection according to partial structure of costume when we select color. Take design of women's dress as an example: we shall enhance the color of lower hem; in this way, when we see the costume at a distance, we can have a feeling that the color gradually changes.

\section{Structure splicing}

(1) Splicing of covering structure. The key of splicing of covering structure is to cover the structure lines of costume, and then adopt splicing technology to carry out partial design to obtain a small, numerous, dense, and loose feeling; through this design, it is able to ignore the curve of body. After we connect some complexes which can be spliced with costume structure, the design is completed. In terms of overall dimension of costume, the cutting line is unrelated with structure line. In this way, the designers can ignore costume structure, just like designing works on a piece of cloth, which can realize combination of color and pattern or material splicing. (2) Splicing of prominent 
structure. (1)If we set separation position according to structure line, the different structure is combined via different cloth or different color. Through this design, it is able to form visual disordered and shocking effect as a whole. If the color is fixed, a beauty of disorder will appear in texture, and different texture can also highlight three-dimensional effect of costume; however, in case of harmonious and natural color matching, it is able to show different human body's curve via different fabric in this combination splicing. (2)If we set structure line as breaking point, each structure can make use of same cloth, which can show different change of structure line. Different from above method, this kind of design can realize a surface-line visual effect, and it needs certain close relation between structure line and human body. Firstly, the structure line shall highlight the curve of body so as to show human's body line. Secondly, the structure line shall have decorative effect except for functional characteristics; therefore, the length, width, and material of structure line shall be coordinated with costume fabric and design style, which is also an important problem which shall be solved by designers.

\section{Development prospect of splicing technology in costume design}

In current clothing industry, the splicing technology is more and more widely applied. Since 19th century, with the appearance of new technology and new materials, the types of materials in clothing industry also become richer and richer. However, as for those designs with many colors and materials, they are generally realized via printing and dyeing, simple decoration or other means. As for marketing mode of mass production, the development of splicing technology has certain limitation. This is also an inevitable problem. Certainly, the further reform and development are also needed in the future.

With continuous social progress and continuous development of humanistic spirit, more and more attention is paid to low-carbon requirement in the modern living ideas; the waste recycling is not merely a slogan, and it also really affects our life. In this era, we not only pay attention to civilization and humanized demand, and also advocate individual development. The waste recycling is not merely to change broken jeans into beggar dress, but to make re-ranking and splicing; certainly, other unrelated articles can be also added. Therefore, as for coordinating and unifying sense of balance, contradiction and contrast sense of shocking, wild and free sense of opening, fine and graceful sense of stability, and admirable sense of development, etc., the perfect breakthrough and development can be realized by use of splicing technology.

\section{References}

[1] Li Zehou: Four Lectures on Aesthetics [M], Guilin: Guangxi Normal University Press, 2009

[2] Mao Qian, Chen Yan: Discussion on Costume Design of Splicing between Knitted and Woven Fabrics [J], Knitting Industry, 2006, (11).

[3] Written by Simon Schiffrhett, Translated by Yuan Yan and Xiao Hong: The Fundamentals of Fashion Design: Research and Design [M], Beijing: China Textile \& Apparel Press, 2009

[4] Liu Dongyuan: Application of Combination of Knitted and Woven Fabrics in Costume Design [J], Knitting Industry, 2006, (12). 